\title{
Leaching behaviour of a galvanic sludge in sulphuric acid and ammoniacal media
}

\author{
J.E. Silva ${ }^{\text {a, } *}$, D. Soares ${ }^{\text {a }}$, A.P. Paiva ${ }^{\text {b }}$, J.A. Labrincha ${ }^{\text {c }}$, F. Castro $^{\text {a }}$ \\ ${ }^{a}$ Mechanical Engineering Department, University of Minho, 4800-058 Guimarães, Portugal \\ ${ }^{\mathrm{b}}$ Department of Chemistry and Biochemistry, Centre of Chemistry and Biochemistry, \\ Faculty of Sciences, University of Lisbon, 1749-016 Lisboa, Portugal \\ ${ }^{c}$ Ceramics and Glass Engineering Department, CICECO, University of Aveiro, 3810-193 Aveiro, Portugal
}

Received 29 September 2004; received in revised form 16 February 2005; accepted 17 February 2005

Available online 6 April 2005

\begin{abstract}
Leaching studies of a sludge produced by the physico-chemical treatment of wastewaters generated by a Ni/Cr plating plant were carried out in both sulphuric acid and ammoniacal media aiming to decide which of them would be the best treatment for this kind of waste material. The dissolution behaviour of some metals $(\mathrm{Cu}, \mathrm{Ni}, \mathrm{Cr}$ and $\mathrm{Zn}$ ) was studied in order to assure the best metal recovery conditions in subsequent processes by the use of some separation methods such as solvent extraction and precipitation techniques. Therefore, the study here presented deals with the first chemical stage of an integrated treatment process. For the sulphuric acid leaching, maximal conversions obtained were $88.6 \% \mathrm{Cu}, 98.0 \% \mathrm{Ni}$ and $99.2 \% \mathrm{Zn}$ for the following experimental conditions: a $100 \mathrm{~g} \mathrm{~L}^{-1}$ acid concentration, a 5:1 liquid-to-solid ratio (L/S), a particle size less than $1 \mathrm{~mm}$, a digestion time of $1 \mathrm{~h}$, a stirring speed of $700 \mathrm{rpm}$ (all at room temperature and under atmospheric pressure). As expected, no selectivity was achieved for the sulphuric acid leaching, despite this option yielding much higher metal ion dissolution when compared with that reached by ammoniacal leaching. The use of this latter medium allowed the extraction of $\mathrm{Cu}$ and $\mathrm{Ni}$ without $\mathrm{Cr}$ species, but rates of conversion were only about $70 \%$ for $\mathrm{Cu}$ and $50 \%$ for $\mathrm{Ni}$, much lower than those obtained for sulphuric acid leaching.
\end{abstract}

(C) 2004 Elsevier B.V. All rights reserved.

Keywords: Galvanic sludge; Sulphuric acid leaching; Ammoniacal leaching; Metals

\section{Introduction}

Metal plating has been identified as an environmental risky industrial sector concerning the potential hazardous nature of its own waste streams, since they often contain reasonable amounts of metals (e.g., nickel, copper, zinc, chromium, etc). The concentration of those metals in the wastewater might reach $30 \%$ (w/w, dry weight) making their recovery an interesting issue as environmental and economical reasons are also subjacent [1]. Despite these arguments, the usual destination for sludges generated in wastewater treatment industrial units in Portugal is their direct disposal as hazardous waste in special landfills located outside the

\footnotetext{
* Corresponding author. Tel.: +351253510 220; fax: +351253516007.

E-mail address: eudes@dem.uminho.pt (J.E. Silva).
}

country. This solution involves enormous costs to the waste producers, since there is a complete absence of accessible alternative treatments within the country [2]. Moreover, the average dimension of the existing units (small-medium enterprises, SMEs) contributes to the lack of real alternatives attempting to an efficient recovery of the valuable species before disposal. Hence, it is extremely important to develop viable ways to recycle those sludges if either environmental or economical aspects are to be taken into account.

A good way to treat and recycle these sludges seems to be achieved by the use of hydrometallurgy. Hydrometallurgical processes have been applied in metallurgy since the Middle Age, and actually one of their utilisations has been in the reduction of the environmental impact of several waste streams, either by lowering the build up of hazardous materials on the earth's crust or by recovering the involved metals for re-use. 
In fact, this area has proved to be a fruitful sector for innovation. The use of hydrometallurgical techniques is becoming more attractive, since the need of high energy requirements or eventual gas collectors and cleaning systems, always necessary in the pyrometallurgical processes, are avoided $[3,4]$.

The most determinant step of a hydrometallurgical process is generally the first, which is the leaching or dissolution of the valuable metals presented in the raw material suffering this sort of treatment. The overall recovery of each metallic species and the difficulty of their separation from other undesirable metals are generally governed by the efficiency and selectivity of the leaching process.

After ammonia, sulphuric acid is the main solvent used in the industrial leaching of laterite, the most important nickel ore, and chalcopyrite, the major source of copper [5-8]. Jha et al. [4] made an extensive review concerning several industrial hydrometallurgical processes, including leaching, to recover zinc from industrial wastes. They have established that the sulphuric acid and ammoniacal solutions are the most effective reagents for the treatment of wastes/secondaries generated in metallurgical industries such as galvanizing, casting, smelting, scrap recycling, etc.

In many hydrometallurgical processes, sulphuric acid has been selected as the cheapest and the most effective leachant $[9,10]$. Ivascanu and Roman [11] studied the extraction of nickel from such kind of spent catalysts through its leaching with sulphuric acid. Almost all the nickel (99\% Ni) was recovered as nickel sulphate by adjustment of a set of suitable operational conditions (sulphuric acid concentration of $80 \%$, reaction time of $50 \mathrm{~min}$ and reaction temperature of $70^{\circ} \mathrm{C}$ ). Al-Mansi and Abdel Monem [10] investigated the possibility of extracting nickel (99\%) from Egyptian spent catalysts and optimal experimental parameters were defined as follows: a 50\% sulphuric acid concentration, a solid-to-liquid ratio of 1:12 and a contact time over $5 \mathrm{~h}$. Abdel-Aal and Rashad [12] focused their work on the kinetics of the leaching process of spent nickel oxide catalysts with sulphuric acid and they obtained extraction levels of about $94 \% \mathrm{Ni}$ by using a $-200+270$ mesh spent particle size, a reaction temperature of $85^{\circ} \mathrm{C}$ for $150 \mathrm{~min}$ and a sulphuric acid concentration of $50 \%$.

On the other hand, ammonia leaching has been applied to metal extraction for a long time [13] and the application of this technology is gradually expanding. In fact, ammonia is widely used as a leachant for its mild alkaline characteristics, ease of use, and potential ability to be recycled [14]. Tsai and Tsai [15] have proposed a flowsheet in which a fly ash residue was firstly leached with an ammoniacal solution containing ammonium sulphate to recover nickel, and then the remaining solid fraction was leached in sodium hydroxide solution to recover vanadium.

The work described in this paper is an attempt to optimise a leaching process to recover nickel, copper and zinc from an industrial galvanic sludge under room temperature/atmospheric pressure and without gas injection. These sludges generally contain a unique mixture of metallic species not normally found in natural ores and concentrates. Furthermore, recycling processes must be as simple and inexpensive as possible. With this idea in mind, a hydrometallurgical process was selected since it can be developed at lower operational costs than those required for the treatment of mineral deposits. This particular paper focuses on the leaching operation itself as a part of an integrated process involving neutralization, precipitation methods, solvent extraction (SX), crystallization, etc, aiming to find an efficient, eco-friendly and economical hydrometallurgical route to recover valuable/hazardous metals and reduce the hazardous character of the waste stream before final disposal.

\section{Experimental}

\subsection{Physico-chemical characteristics of the sludge}

The waste used in this study is a sludge produced by the physico-chemical treatment of wastewaters generated by a $\mathrm{Ni} / \mathrm{Cr}$ plating plant located at Braga, in the north of Portugal. This sludge is mostly composed of metal hydroxide gels, sulphate salts and occasionally chlorides, thus showing a relatively complex structure and a reasonable high chemical variability, depending on the producing unit, time, product specifications, processing/operation variations and stocking age [16]. The main metal species are combined forming nitrogen-, oxygen-, hydrogen-, sulphurand carbon-containing compounds.

The characterisation of the sludge involved determinations of density (Micromerits helium picnometry, model 1330) moisture content (Adam balance, model AMB 310) and specific surface area (SA) for samples either in a dry or dispersed form (BET method - Gemini II 2370 equipment [17]). A mass of $30 \mathrm{~kg}$ of sludge was completely dried at $105^{\circ} \mathrm{C}$, and then grounded and sieved. Particles of a size $<1.0 \mathrm{~mm}$ were selected. The powdered material was thoroughly homogenised and representative samples were taken for chemical characterisation and subsequent leaching tests. The chemical composition (major elements) of the sludge was determined by submitting three small representative samples to digestion with aqua regia. The resulting solutions were analysed by atomic absorption spectrometry (AAS method, GBC 904 AA device). The main physico-chemical characteristics of the sludge are presented in Table 1.

\subsection{Leaching experiments}

Leaching experiments with sulphuric acid and ammoniacal solutions were carried out at room temperature in semiclosed, cylindrical $2000 \mathrm{~mL}$ glass beakers for $24 \mathrm{~h}$. A stirring speed of a $700 \mathrm{rpm}$, with a magnetic stirrer, was set up to ensure the full suspension of particles and to improve the liquid-to-solid phase contact. All the chemicals used in this work were of pure grade. 
Table 1

Relevant physico-chemical characteristics of the sludge

\begin{tabular}{|c|c|c|c|c|c|}
\hline Density $\left(\mathrm{g} \mathrm{cm}^{-3}\right)$ & 2.24 & & & & \\
\hline $\mathrm{H}_{2} \mathrm{O}(\%)$ & 87.6 & & & & \\
\hline $\mathrm{SA}\left(\mathrm{m}^{2} \mathrm{~g}^{-1}\right)$ & 32.2 & & & & \\
\hline \multicolumn{6}{|c|}{ Elements in the dried sludge (wt.\%) } \\
\hline $\mathrm{Al}$ & 0.52 & $\mathrm{Fe}$ & 1.53 & $\mathrm{~Pb}$ & 0.36 \\
\hline $\mathrm{Ba}$ & 0.02 & $\mathrm{~K}$ & 0.60 & $\mathrm{~S}$ & 5.73 \\
\hline $\mathrm{Ca}$ & 0.25 & $\mathrm{Mg}$ & 0.11 & $\mathrm{Si}$ & 28.04 \\
\hline $\mathrm{Cl}$ & 0.12 & $\mathrm{Mn}$ & 0.27 & $\mathrm{Sn}$ & 0.05 \\
\hline $\mathrm{Cr}$ & 7.04 & $\mathrm{Ni}$ & 9.48 & $\mathrm{Ti}$ & 0.07 \\
\hline $\mathrm{Cu}$ & 4.20 & $\mathrm{P}$ & 4.05 & $\mathrm{Zn}$ & 2.96 \\
\hline
\end{tabular}

Based on the knowledge of the sludge composition and assuming that the main reactions involving $\mathrm{Cr}-, \mathrm{Cu}-, \mathrm{Fe}-, \mathrm{Ni}-$ and $\mathrm{Zn}$-hydroxides with sulphuric acid are of the type:

$\mathrm{Ni}(\mathrm{OH})_{2}+\mathrm{H}_{2} \mathrm{SO}_{4} \rightarrow \mathrm{NiSO}_{4}+2 \mathrm{H}_{2} \mathrm{O}$

a simple calculation of the stoichiometric amount of sulphuric acid needed to neutralise the hydroxides was done aiming to obtain a $20 \mathrm{~g} \mathrm{~L}^{-1} \mathrm{Ni}$ as the final concentration in the leaching solution (a slight margin of confidence of about $10 \%$ was assumed). As previously mentioned, the sludge is a very complex multi-component-system consisting of a few major components and a lot of minor/trace constituents. Therefore, it should not be forgotten that several interactions eventually occurring between the ions in solution had to be neglected. On this basis, a ratio of about $100 \mathrm{~g} \mathrm{H}_{2} \mathrm{SO}_{4}$ per $100 \mathrm{~g}$ of dried sludge was calculated. This determination was used to estimate the sulphuric acid consumption and the $\mathrm{L} / \mathrm{S}$ ratio on the leaching experiments.

In ammoniacal leaching tests, the L/S ratio was kept constant at 10:1. Aqueous solutions were prepared by varying the dissolution of known amounts of reagents grade $\mathrm{NH}_{3}$ and $\left(\mathrm{NH}_{4}\right)_{2} \mathrm{CO}_{3}$ in distilled water.

During leaching tests, samples were withdrawn at regular intervals using a pipette $(10 \mathrm{~mL})$ and, after filtration, the resulting solution was analysed for metal elements by atomic absorption spectrometry (AAS). The remaining cake was analysed by X-ray fluorescence spectrometry (XRF, Philips X'UNIQUE II).

The conditions adopted for each set of experiments are shown in Tables 2 and 3 for sulphuric acid and ammoniacal leaching, respectively.

Table 2

Sulphuric acid leaching conditions adopted in the different experiments

\begin{tabular}{lllllll}
\hline Condition & \multicolumn{5}{l}{ Test number } \\
\cline { 2 - 7 } & 1 & 2 & 3 & 4 & 5 & 6 \\
\hline $\mathrm{H}_{2} \mathrm{SO}_{4}\left(\mathrm{~g} \mathrm{~L}^{-1}\right)$ & 100 & 100 & 100 & 200 & 200 & 200 \\
$\mathrm{~L} / \mathrm{S}$ ratio & $5: 1$ & $10: 1$ & $20: 1$ & $5: 1$ & $10: 1$ & $20: 1$
\end{tabular}

\section{Results and discussion}

\subsection{Physico-chemical characteristics}

As can be seen in Table 1, the sludge contains high contents of valuable metals such as $\mathrm{Cu}, \mathrm{Ni}$ and $\mathrm{Zn}$, though it presents a much higher concentration $(60 \mathrm{wt} . \%)$ of silica, an inert material. At the same time, several other metal species are present, like $\mathrm{Cr}, \mathrm{Fe}$ and $\mathrm{Pb}$; these latter metals can be considered contaminants as they affect the leaching process through their co-dissolution together with the valuable metals, thus reducing the purity of the resulting liquor leach. It can also be noted that the moisture level is high, which means that without a previous drying operation the costs for transportation/disposal of the sludge are high. A reference value collected amongst some Portuguese waste management companies rounds $100 € / \mathrm{t}$ plus transportation at long distances, this fee including only disposal facilities. Currently, a significant part of the total weight of freight transported from Portugal to Spain is waste, this situation also denoting high energy consumption. Therefore, before land filling, it would be convenient to carry out an efficient sludge dehydration operation, which could represent an approximate reduction from 4-20 to 1 in the waste volume if common filter-pressing operations are to be considered [18].

\subsection{Leaching experiments}

Results given in Tables 4 and 5 show the concentrations $\left(\mathrm{g} \mathrm{L}^{-1}\right)$, weight percentages of each element dissolved, and also the $[\mathrm{Ni}+\mathrm{Cu}+\mathrm{Zn}] /[\mathrm{Cr}+\mathrm{Fe}+\mathrm{Pb}]$ ratio, calculated from the metal element concentrations, for a set of six experiments conducted in different conditions, as detailed in Tables 2 and 3. This latter ratio denotes the selectivity achieved for the valuable metals in relation to those considered as impurities. The leaching efficiency is defined as the ratio of the leached amount of a given element over the total amount of this element in the sample of galvanic sludge. Moreover, a mass balance was done taking into account the fraction of unreacted sludge, in order to confirm the percentages of metal elements of interest leached at the end of the tests.

\subsubsection{Effect of reagent concentration}

Concerning the sulphuric acid leaching, as can be concluded from analysis of Tables 2 and 4, the increase in the ionic strength of the solution beyond the calculated stoichiometric amount of $100 \mathrm{~g} \mathrm{~L}^{-1} \mathrm{H}_{2} \mathrm{SO}_{4}$ does not improve the concentration of the valuable metals in solution. In Table 4, the comparison of results obtained by using fixed L/S ratios (pairs $\{1,4\},\{2,5\}$ and $\{3,6\}$ ), shows that only the concentrations of the undesirable elements $\mathrm{Fe}$ and $\mathrm{Pb}$ significantly increased with the increasing sulphuric acid concentration. In test 1 , in which the exact acid concentration required for the calculated stoichiometric amount was used, 
Table 3

Ammoniacal leaching conditions followed in the different tests

\begin{tabular}{|c|c|c|c|c|c|c|}
\hline \multirow[t]{2}{*}{ Reagent } & \multicolumn{6}{|l|}{ Test number } \\
\hline & 1 & 2 & 3 & 4 & 5 & 6 \\
\hline Ammonia $\left(\mathrm{g} \mathrm{L}^{-1}\right)$ & 0 & 50 & 100 & 100 & 150 & 200 \\
\hline Amm. carbonate $\left(\mathrm{g} \mathrm{L}^{-1}\right)$ & 100 & 100 & 0 & 100 & 150 & 200 \\
\hline $\mathrm{pH}$ & $8.54 \pm 0.64$ & $9.63 \pm 0.13$ & $11.32 \pm 0.41$ & $9.61 \pm 0.17$ & $9.75 \pm 0.15$ & $9.85 \pm 0.19$ \\
\hline
\end{tabular}

Table 4

Effect of different leachant conditions in the leaching of $\mathrm{Cu}, \mathrm{Cr}, \mathrm{Fe}, \mathrm{Ni}, \mathrm{Pb}$ and $\mathrm{Zn}$ by sulphuric acid

\begin{tabular}{llllllll}
\hline Leaching test & \multicolumn{6}{l}{ Leached metal ions $\left(\mathrm{g} \mathrm{L}^{-1}\right)(\%)$} \\
\cline { 2 - 8 } & $\mathrm{Cu}$ & $\mathrm{Cr}$ & $\mathrm{Fe}$ & $\mathrm{Ni}$ & $\mathrm{Pb}$ & $\mathrm{Zn}$ & {$[\mathrm{Ni}+\mathrm{Cu}+\mathrm{Zn}] /[\mathrm{Cr}+\mathrm{Fe}+\mathrm{Pb}]$} \\
\hline 1 & $7.45(88.6)$ & $13.83(98.2)$ & $1.13(36.8)$ & $18.59(98.0)$ & $0.04(5.6)$ & $5.87(99.2)$ & 2.13 \\
2 & $3.72(88.5)$ & $6.47(91.9)$ & $0.57(37.1)$ & $8.6(90.8)$ & $0.01(3.0)$ & $2.83(95.5)$ & 2.15 \\
3 & $1.77(84.1)$ & $3.48(98.8)$ & $0.27(35.8)$ & $4.7(99.2)$ & $0.002(2.5)$ & $1.43(96.3)$ & 2.10 \\
4 & $6.52(77.6)$ & $13.97(99.2)$ & $1.53(50.0)$ & $18.08(95.4)$ & $0.04(4.9)$ & $5.31(89.8)$ & 1.93 \\
5 & $3.28(78.0)$ & $5.97(84.8)$ & $0.7(45.9)$ & $8.8(92.9)$ & $0.02(5.5)$ & $2.83(95.7)$ & 2.23 \\
6 & $1.66(79.0)$ & $2.9(82.3)$ & $0.34(44.2)$ & $4.19(88.4)$ & $0.01(4.0)$ & $1.31(88.6)$ & 2.21 \\
\hline
\end{tabular}

Leaching conditions: $t=24 \mathrm{~h}$; stirring speed $=700 \mathrm{rpm}$, values in brackets give the percentage of dissolution for each metal species.

maximal simultaneous conversions of $\mathrm{Cu}(88.6 \%), \mathrm{Ni}$ $(98.0 \%)$ and $\mathrm{Zn}(99.2 \%)$ were reached.

Regarding the ammoniacal leaching, the comparison of the results obtained on tests 1 and 3 (see Table 5) leads to the conclusion that the presence of ammonium carbonate has a stronger influence than ammonia in the metal ion dissolution. As a whole, however, it can be considered that the presence and the combined effect of both reagents (ammonia and ammonium carbonate) are fundamental to an effective dissolution of the metal ion elements [19]. This assumption can be confirmed if Tables 3 and 5 are directly compared: for example, the extraction of $\mathrm{Ni}$ sharply rises by increasing the ionic strength of the solution containing both ammonia and ammonium carbonate, particularly for tests 4-6. Burkin [20] has established that $\mathrm{Cu}$ could not be dissolved in solutions of ammonium salts containing no free ammonia. However, the addition of ammonium ions increases the rate of solution in ammonia up until a certain ammonia-ammonium ratio is reached, where further addition has no effect.

For the general conditions tested, one can say that sulphuric acid proved to be an efficient leaching medium for the most valuable metals present in the sludge, although with a quite low selectivity, whereas the inverse situation occurred when ammoniacal media was used instead.

\subsubsection{Effect of liquid/solid ratio and $p H$}

For the sulphuric acid leaching, the comparison of results obtained from the tests performed by utilising the same acid concentration, i.e., $\{1,2,3\}$ or $\{4,5,6\}$ groups - Table 4 shows that no significant variations were detected on the dissolution of the valuable metals with the increase in the $\mathrm{L} / \mathrm{S}$ ratio. This trend might indicate that equilibrium leaching conditions were reached even by using the lower L/S ratio. Accordingly, test 1 seems to be the best in conjugating a higher relative dissolution of valuable metals with a lower sulphuric acid consumption.

In the ammoniacal leaching experiments, the $\mathrm{L} / \mathrm{S}$ ratio was kept constant for all the tests. However, the $\mathrm{pH}$ control in all these experiments was of fundamental importance. As can be inferred from analysis of Tables 3 and 5 , the dissolution of $\mathrm{Cu}$, $\mathrm{Ni}$ and $\mathrm{Zn}$ was higher for average $\mathrm{pH}$ values closer to $\mathrm{pH} 10$. In tests 1 and $3, \mathrm{pH}$ values were somewhat distant from that value, and results were not so constant (with relatively high standard deviations). It is known that ammonium carbonate

Table 5

Effect of different leachant conditions in the leaching for $\mathrm{Cu}, \mathrm{Cr}, \mathrm{Fe}, \mathrm{Ni}, \mathrm{Pb}$ and $\mathrm{Zn}$ in ammoniacal media

\begin{tabular}{|c|c|c|c|c|c|c|}
\hline \multirow[t]{2}{*}{ Leaching test } & \multicolumn{6}{|c|}{ Leached metal ions $\left(\mathrm{g} \mathrm{L}^{-1}\right)(\%)$} \\
\hline & $\mathrm{Cu}$ & $\mathrm{Cr}$ & $\mathrm{Ni}$ & $\mathrm{Pb}$ & $\mathrm{Zn}$ & {$[\mathrm{Ni}+\mathrm{Cu}+\mathrm{Zn}] /[\mathrm{Cr}+\mathrm{Pb}]$} \\
\hline 1 & $1.24(30.0)$ & $0.07(1.2)$ & $0.98(10.3)$ & udl & $0.36(23.0)$ & 35.86 \\
\hline 2 & $1.11(28.0)$ & $0.13(1.8)$ & $1.19(20.6)$ & $0.009(25.0)$ & $0.45(18.0)$ & 20.24 \\
\hline 3 & $0.74(18.6)$ & $0.02(0.5)$ & $0.46(5.6)$ & udl & $0.13(8.5)$ & 83.44 \\
\hline 4 & $1.88(44.9)$ & $0.55(7.7)$ & $2.94(30.4)$ & $0.003(7.5)$ & $0.89(42.0)$ & 10.22 \\
\hline 5 & $2.59(61.4)$ & $1.09(14.3)$ & $4.25(42.3)$ & $0.009(25.0)$ & $1.21(47.5)$ & 7.29 \\
\hline 6 & $2.90(69.7)$ & $1.52(19.7)$ & $4.75(49.4)$ & $0.004(12.5)$ & $1.37(51.5)$ & 5.92 \\
\hline
\end{tabular}

Leaching conditions: $t=24 \mathrm{~h} ; \mathrm{L} / \mathrm{S}$ ratio $=10: 1$; stirring speed $=700 \mathrm{rpm}$, udl - values under the detection limit, Fe concentrations were always under the detection limit, values in brackets give the percentage of dissolution for each metal species. 
plays an important role in buffering the leaching solution, thus preventing a $\mathrm{pH}$ rise to the point where nickel and copper can precipitate as their hydroxides ( $\mathrm{pH}$ beyond 10). In addition, $\mathrm{NH}_{4}{ }^{+}$ions, supplied by the ammonium salt, can favour the occurrence of amine complex reactions by removing $\mathrm{OH}^{-}$ ions [7,21]. Therefore, a critical compromise between the ionic strength and $\mathrm{pH}$ should be found, in order to enhance the leaching efficiency of ammoniacal media for the valuable metals contained in the sludge.

\subsubsection{Selectivity}

The selectivity values obtained for the sulphuric acid leaching tests were quite close, however a relatively higher $[\mathrm{Ni}+\mathrm{Cu}+\mathrm{Zn}] /[\mathrm{Cr}+\mathrm{Fe}+\mathrm{Pb}]$ ratio (2.23) was achieved in test
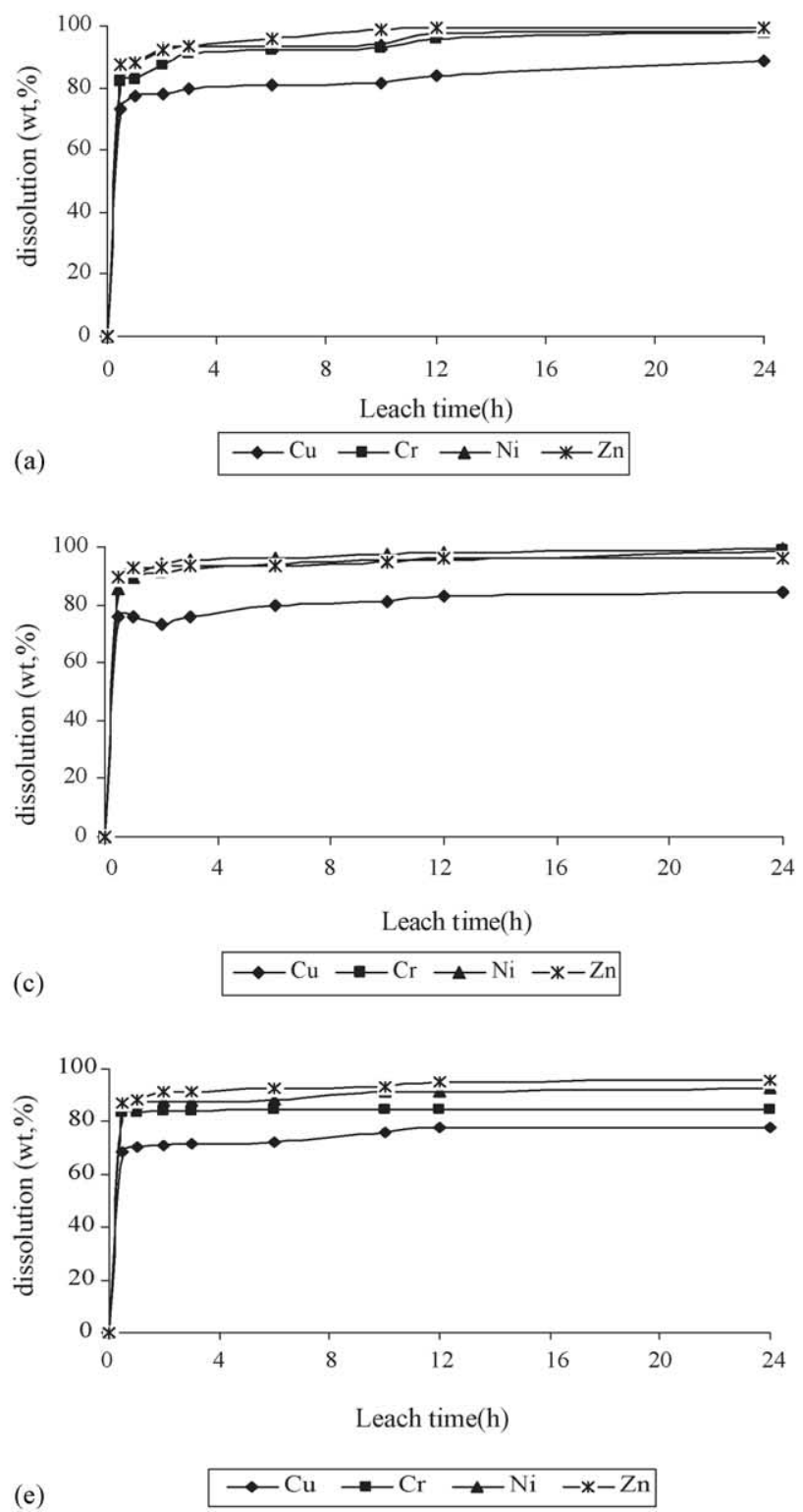

(e)

$$
\multimap \mathrm{Cu} \rightarrow-\mathrm{Cr} \rightarrow \mathrm{Ni}-*-\mathrm{Zn}
$$

5 - Table 4 - thus representing the maximum selectivity ratio attained for a final leach liquor. However, this test involved a higher sulphuric acid consumption and therefore, balancing the experimental conditions and overall results obtained for both tests 1 and 5 when observed under the light of the general aims designed for this work, test 5 was considered less favourable than test 1 .

In the ammoniacal leaching, as can be inferred from results of Table 5, $\mathrm{Cu}$ is the most readily leached component, whereas $\mathrm{Cr}$ seems to be the main element rejected within the system, since there is an amount of $\mathrm{Cr}$ relatively abundant when compared to the contents of $\mathrm{Pb}$ and Fe elements in the feed sludge. Richardson [22] arguments that ammoniacal leach liquors reject iron and offer excellent kinetics
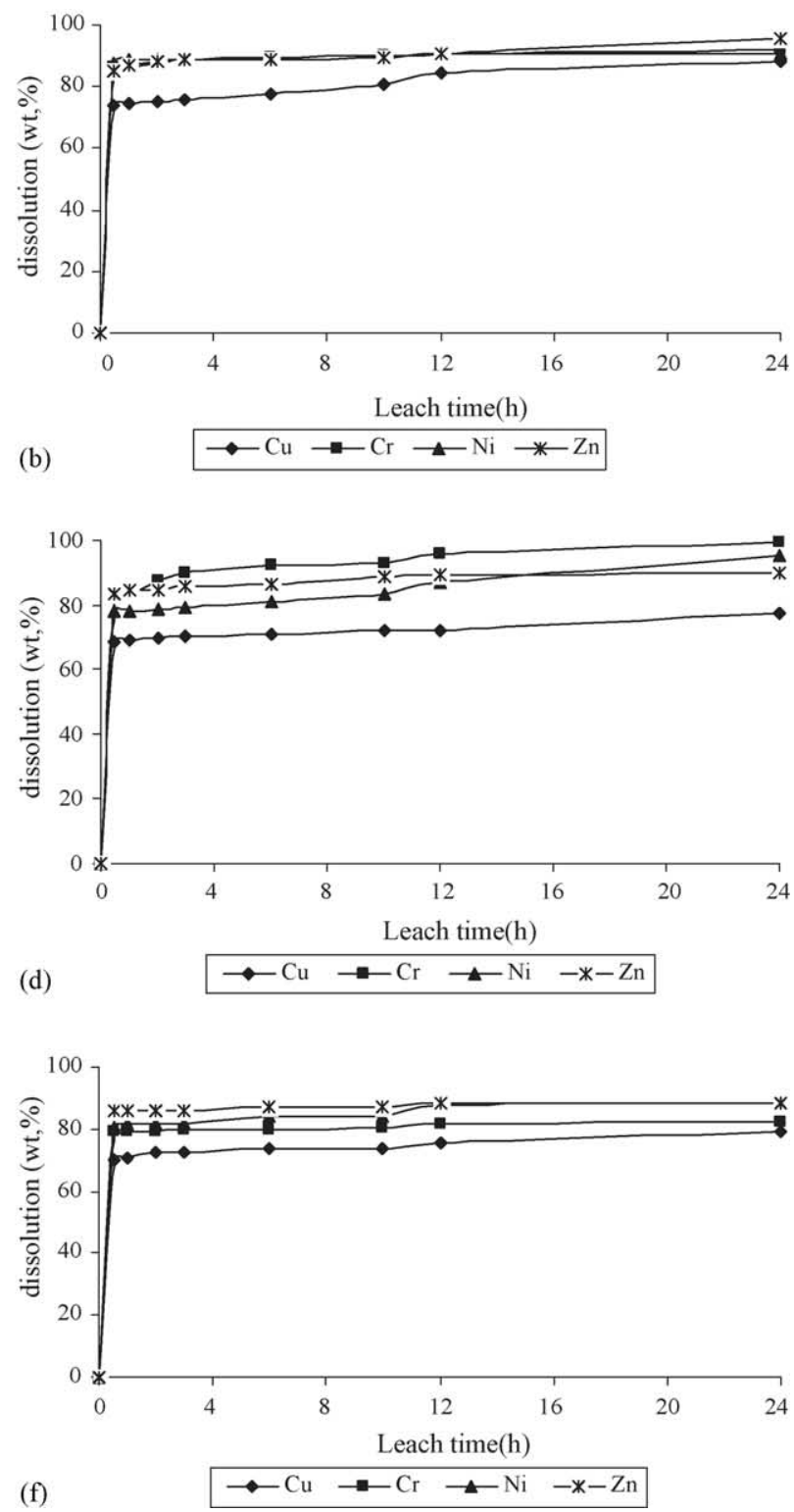

Fig. 1. Effect of leaching time on the dissolution of the major metal elements contained in a galvanic sludge by a sulphuric acid leachant: (a) L/S ratio 5:1;

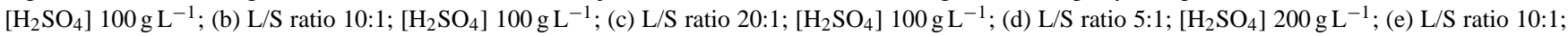
$\left[\mathrm{H}_{2} \mathrm{SO}_{4}\right] 200 \mathrm{~g} \mathrm{~L}^{-1}$; (f) L/S ratio $20: 1 ;\left[\mathrm{H}_{2} \mathrm{SO}_{4}\right] 200 \mathrm{~g} \mathrm{~L}^{-1}$. 
with respect to $\mathrm{Cu}$ metal dissolution, and the results found in this work for the $[\mathrm{Cu}+\mathrm{Ni}+\mathrm{Zn}] /[\mathrm{Cr}+\mathrm{Pb}]$ ratio indicate that test 3 presented in Table 5 assures optimal selectivity conditions. Nevertheless, the quite low concentrations of valuable metal elements in the leach solution obtained in test 3, with only ammonia as reagent, is obviously an important drawback. Hence, the simultaneous use of ammonia and ammonium carbonate in similar proportions seems to enhance the efficiency of the leaching process, despite the decrease of the system selectivity towards the valuable elements. In any case, if the balance between reagent consumption and effective metal ion dissolution efficiency is taken into account, test 6 corresponds to the optimal conditions, since the dissolution of $\mathrm{Cu}, \mathrm{Ni}$ and $\mathrm{Zn}$ were the highest ones while the presence of $\mathrm{Cr}$ and $\mathrm{Pb}$ was minimal.

\subsubsection{Leaching time}

The dependence of the metal ion dissolution by sulphuric acid (expressed as wt.\% of their initial concentration) on leaching time is shown in Fig. 1(a-f) for different testing conditions (tests $1-6$, respectively). It is possible to conclude that the contact/reaction time between the solid and liquid phases did not reveal to be a relevant parameter, $1 \mathrm{~h}$ seeming to be enough for the systems to achieve equilibrium. In fact, for almost all the metal elements of interest, their dissolution by sulphuric acid solutions is completed within about $1 \mathrm{~h}$ or

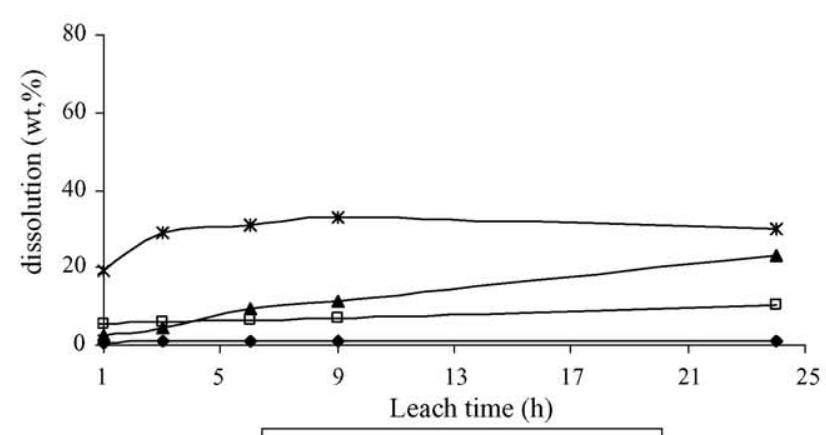

(a)
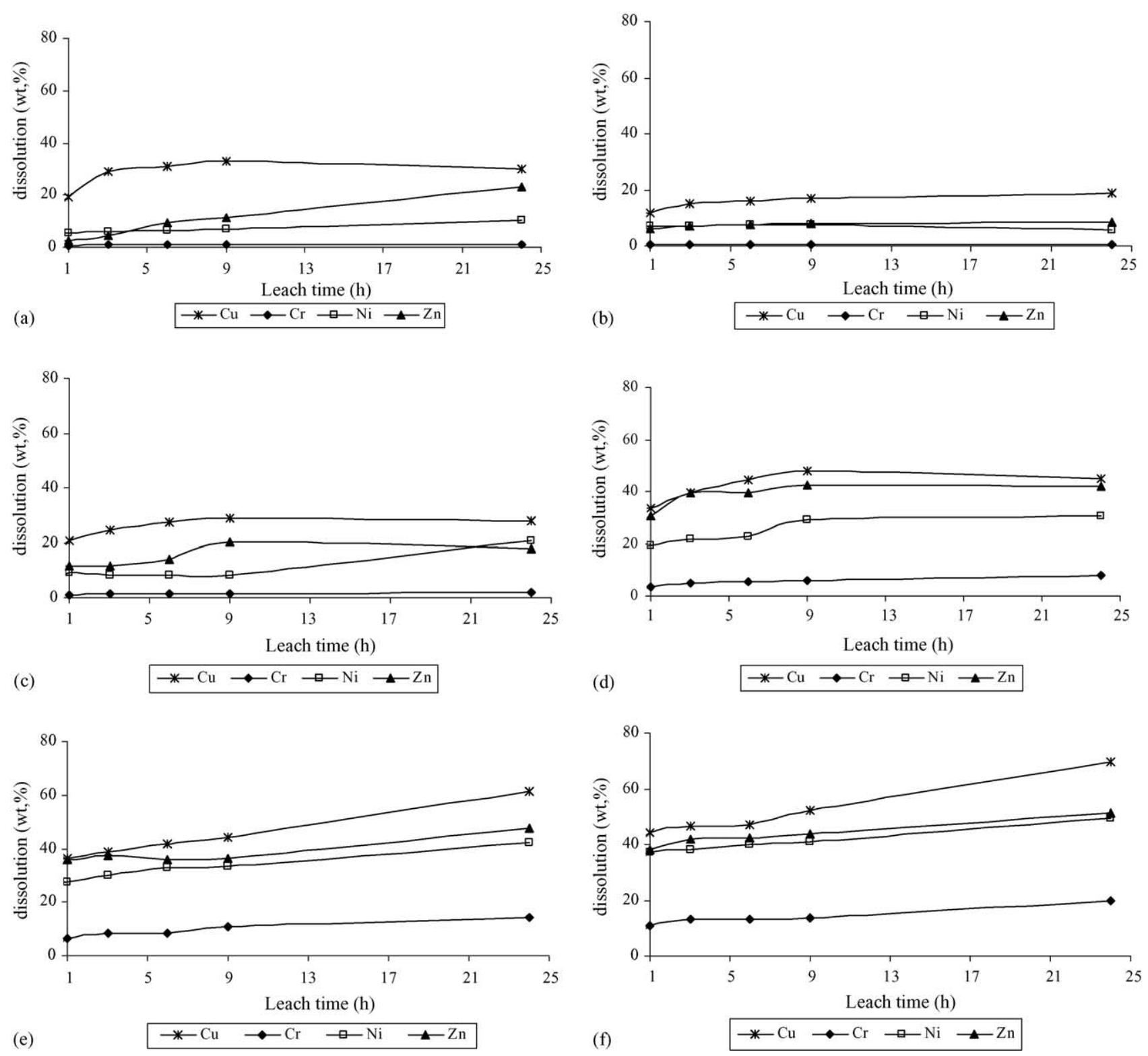

Fig. 2. Effect of leaching time on the dissolution of the major metal elements contained in a galvanic sludge by ammoniacal media: (a) $\mathrm{L} / \mathrm{S}$ ratio $10: 1 ;$ [ $\left.\mathrm{NH}_{3}\right]$ $0 \mathrm{~g} \mathrm{~L}^{-1} ;\left[\left(\mathrm{NH}_{4}\right)_{2} \mathrm{CO}_{3}\right] 100 \mathrm{gL}^{-1}$; (b) L/S ratio $10: 1 ;\left[\mathrm{NH}_{3}\right] 50 \mathrm{gL}^{-1}$; $\left[\left(\mathrm{NH}_{4}\right)_{2} \mathrm{CO}_{3}\right] 100 \mathrm{~g} \mathrm{~L}^{-1}$; (c) L/S ratio $10: 1 ;\left[\mathrm{NH}_{3}\right] 100 \mathrm{gL}^{-1} ;\left[\left(\mathrm{NH}_{4}\right)_{2} \mathrm{CO}_{3}\right] 0 \mathrm{~g} \mathrm{~L}^{-1} ;(\mathrm{d})$ $\mathrm{L} / \mathrm{S}$ ratio 10:1; $\left[\mathrm{NH}_{3}\right] 100 \mathrm{~g} \mathrm{~L}^{-1}$; $\left[\left(\mathrm{NH}_{4}\right)_{2} \mathrm{CO}_{3}\right] 100 \mathrm{~g} \mathrm{~L}^{-1}$; (e) $\mathrm{L} / \mathrm{S}$ ratio $10: 1 ;\left[\mathrm{NH}_{3}\right] 150 \mathrm{~g} \mathrm{~L}^{-1} ;\left[\left(\mathrm{NH}_{4}\right)_{2} \mathrm{CO}_{3}\right] 150 \mathrm{~g} \mathrm{~L}^{-1}$; (f) L/S ratio $10: 1 ;\left[\mathrm{NH}_{3}\right] 200 \mathrm{~g} \mathrm{~L}^{-1}$; $\left[\left(\mathrm{NH}_{4}\right)_{2} \mathrm{CO}_{3}\right] 200 \mathrm{~g} \mathrm{~L}^{-1}$. 
less. In general, the extent of dissolution of $\mathrm{Cr}, \mathrm{Ni}$ and $\mathrm{Zn}$ is comparable, whereas the dissolution of $\mathrm{Cu}$ is systematically lower. This latter result is quite obvious, as sulphuric acid is not the most suitable solvent to dissolve $\mathrm{Cu}$.

On the other hand, the effect of the leaching time on the dissolution of the metal ion elements (expressed as wt.\% of the initial concentration) by ammoniacal media is shown in Fig. 2(a-f) for different testing conditions (tests 1-6, respectively). Some important trends are easily visible: (i) firstly, the total dissolved amounts of all species were relatively low after a $24 \mathrm{~h}$ reaction, in contrast with the results obtained for the leaching efficiencies denoted by sulphuric acid; (ii) secondly, with the ammonia/ammonium carbonate leaching solutions, $\mathrm{Cu}$ was always the easiest metal to dissolve, while $\mathrm{Cr}$ dissolution was systematically lower than the ones observed for the other metal species.

Bell et al. [6] studied the leaching of chalcopyrite with ammoniacal solutions and established that temperature, ammonium salt concentration and the interaction between these two factors were the relevant and influent parameters on the extraction of $\mathrm{Cu}$. In particular, the breakdown of ammonium hydroxide into water and ammonia was found to be a crucial step, since ammonia is known to be an active contributor to the $\mathrm{Cu}$ leaching reaction. Blanco et al. [14], in their work about $\mathrm{Zn}$ wastes leaching in ammonia/ammonium carbonate solution, also concluded that temperature should be as high as possible, but less than boiling point of the ammonia/ammonium carbonate solution used. Therefore, an increase of temperature for the systems under study would probably be a good option to explore in the future, in order to promote the leaching reaction kinetics and to increase the extracted amounts of the metallic elements of interest. However, this route would involve extra costs with higher energy consumptions.

Another possibility that could be considered would be the application of a dynamic leaching process in repeated steps, involving leachant renewal. Further work is in progress to promote that operation, in order to evaluate the possibility of reaching higher dissolution yields while keeping a high selectivity towards the metals of interest. The economical feasibility of this alternative at a pilot plant scale would also be an important key step to evaluate, the ammonia regeneration process surely being an important contribution.

On the other hand, subsequent processes have already been performed successfully using the liquor generated from the sulphuric acid leaching. Concerning the copper and chromium metal species, $\mathrm{Cu}$ was recovered as a powder metal by a cementation process, whereas the characterisation of the $\mathrm{Cr}-\mathrm{CaCO}_{3}$ precipitate is now underway, as well as some tests aiming to evaluate its probable introduction in refractory materials. In addition, zinc and nickel separation was successfully carried out by solvent extraction (SX) [23]. Zinc was recovered in the final stripping process whereas nickel remained in the feed aqueous solution; finally, nickel sulphate could be produced from a quite pure aqueous solution by the salt crystallization method. Detailed conditions and results of the SX experiments are already under publication [23]; $\mathrm{Cu}$ cementation and $\mathrm{Cr}$ precipitation methods, as well as their eventual useful applications, will certainly be the target of future papers, to be prepared soon.

\section{Conclusions}

The leaching efficiency of sulphuric acid towards several metallic elements such as $\mathrm{Ni}, \mathrm{Zn}$ and even $\mathrm{Cu}$, contained in a galvanic sludge, is much higher than that observed by using ammonia/ammonium carbonate. In fact, the metals dissolution by $\mathrm{H}_{2} \mathrm{SO}_{4}$ is almost complete within $1 \mathrm{~h}$, while leached levels reached upon by ammoniacal solutions are only half (for $\mathrm{Ni}$ and $\mathrm{Zn}$ ) or two thirds (for $\mathrm{Cu}$ ) of those registered in acidic media, even after $24 \mathrm{~h}$. Then, amongst all the leaching experiments carried out with $\mathrm{H}_{2} \mathrm{SO}_{4}$, conditions followed for test $1\left(100 \mathrm{~g} \mathrm{~L}^{-1} ; 5: 1 \mathrm{~L} / \mathrm{S}\right.$ ratio $)$ have assured the most favourable economical situation, while maximum selectivity for the desired valuable metals was achieved in test 5 . In fact, test 1 allowed the effective treatment of a higher amount of sludge with the lowest sulphuric acid consumption. In addition, an increase of the acid concentration resulted in a higher dissolution of the trace elements, mainly $\mathrm{Fe}$, and this latter achievement might be detrimental for the recovery of the valuable metals from the solution in subsequent stages. The only positive aspect observed in ammoniacal leaching experiments developed until now was the relatively high selectivity against $\mathrm{Cr}$.

Subsequent processes have already been performed successfully using the liquors generated from the sulphuric acid leaching, which allowed the effective recovery of some valuable metals. Anyway, further work at a pilot-plant level is now in progress in order to confirm the promising results already achieved, as well as to test the viability of other leaching alternatives based on ammoniacal digestion systems.

\section{References}

[1] J.A. Magalhães, Inertization of galvanic sludge by its incorporation in ceramic bodies, Ph.D. Thesis, University of Minho, 2002, pp. 311.

[2] D.A. Pássaro, Report: waste management in Portugal between 1996 and 2002, Waste Manage. 23 (2003) 97-99.

[3] D.G.E. Kerfoot, D.R. Weir, The hydro and electrometallurgy of nickel and cobalt, in: G.P. Tyroler, C.A. Landolt (Eds.), Proceedings of the Symposium sponsored by the CuNiCo and Non-Ferrous Pyrometallurgy Committees of the Metallurgical Society, 25-28 January, The Metallurgical Society, Inc. Publications, Phoenix, Arizona, USA, 1988, pp. 241-267.

[4] M.K. Jha, V. Kumar, R.J. Singh, Review of hydrometallurgical recovery of zinc from industrial wastes., Resour. Conserv. Recycl. 33 (2001) 1-22.

[5] I. Halikia, Parameters influencing kinetics of nickel extraction from a Greek laterite during leaching with sulphuric acid at atmospheric pressure, Trans. Instn. Min. Metall. 100 (1991) C154-C164.

[6] S.L. Bell, G.D. Welch, P.G. Bennett, Development of ammoniacal lixiviants for the in-situ leaching of chalcopyrite, Hydrometallurgy 39 (1995) 11-23. 
[7] Y.C. Guan, K.N. Han, The leaching kinetics of chalcopyrite $\left(\mathrm{CuFeS}_{2}\right)$ in ammonium iodide solutions with iodine., Metall. Mater. Trans. B 28B (1997) 979-1000.

[8] S. Prasad, B.D. Pandey, Alternative processes for treatment of chalcopyrite - a review, Min. Eng. 11 (8) (1998) 763-781.

[9] D.H. Rubisov, V.G. Papangelakis, Sulphuric acid pressure leaching of laterites - speciation and prediction of metal solubilities "at temperature", Hydrometallurgy 58 (2000) 13-26.

[10] N.M. Al-Mansi, N.M. Abdel Monem, Recovery of nickel oxide from spent catalyst, Waste Manage. 22 (2002) 85-90.

[11] S.T. Ivascanu, O. Roman, Nickel recovery from spent catalysts: I. Solvation process, Bul. Inst. Politeh. Iasi, Sect. II 2 (21) (1975) 47.

[12] E.A. Abdel-Aal, M.M. Rashad, Kinetic study on the leaching of spent nickel oxide catalyst with sulphuric acid, Hydrometallurgy 74 (2004) 189-194.

[13] M.A. Hewedi, L.F. Engle, The NH-CO-HO system at atmospheric pressure in non-ferrous extractive 322 metallurgy, in: Proceedings of the International Symposium on Hydrometallurgy, Chicago, 1973, pp. 806-858.

[14] L.J.L. Blanco, V.F.M. Zapata, D.D.J. Garcia, Statistical analysis of laboratory results of $\mathrm{Zn}$ wastes leaching, Hydrometallurgy 54 (1999) $41-48$.
[15] S.-L. Tsai, M.-S. Tsai, Resour. Conserv. Recycl. 22 (1998) 163-176.

[16] J.M. Magalhães, J.E. Silva, F.P. Castro, J.A. Labrincha, Effect of experimental variables on the inertization of galvanic sludges in claybased ceramics, J. Hazard. Mat. 106B (2004) 139-147.

[17] S. Brunauer, P.H. Emmet, E. Teller, Adsorption of gases in multimolecular layers, J. Am. Chem. Soc. 60 (1938) 309-319.

[18] http://www.nmfrc.org/bluebook/sec626.htm - Pollution Prevention and Control Technologies for Plating Operations, 1998.

[19] D. Bingol, M. Canbazoglu, S. Aydogan, Dissolution kinetics of malachite in ammonia/ammonium carbonate leaching, Hydrometallurgy 76 (2004) 55-62.

[20] A.R. Burkin, The Chemistry of Hydrometallurgical Process, E\&F Spon, London, 1966, pp. 157.

[21] C.K. Gupta, T.K. Mukherjee, Hydrometallurgy in Extraction Processes, vol. I, CRC Press, Boca Raton, 1990, pp. 225.

[22] H.W. Richardson, Hydrometallurgical reclamation of copper from metal-bearing waste, Handbook of Copper Compounds and Applications, H. Wayne Richardson, New York, 1997, pp. 339-342.

[23] J.E. Silva, A.P. Paiva, D. Soares, A. Labrincha, F. Castro, Solvent extraction applied to the recovery of heavy metals from galvanic sludge. J. Hazard. Mater., in press, doi:10.1016/j.jhazmat. 2004.12.008. 